\title{
EREBEA
}

Revista de Humanidades y Ciencias Sociales

Núm. 9 (2019), pp. 37-62

ISSN: 0214-0691

http://dx.doi.org/10.33776/erebea.v9i0.4027

\section{SOBRE EL PAPEL DE LA TOPONIMIA EN LA INTERPRETACIÓN DEL PAISAJE. UN APUNTE TEÓRICO}

\author{
Joan Tort Donada \\ Universitat de Barcelona
}

RESUMEN

Se exploran en este artículo las posibilidades de abordar la toponimia desde una óptica geográfica y, especialmente, como herramienta para el análisis y la interpretación del paisaje. Se parte de la premisa que el topónimo, o nombre de lugar, es un concepto de naturaleza plural que integra tres dimensiones: una, lingüística; otra, geográfica, y una tercera, histórica. Sobre esta base, se plantean las líneas fundamentales de su utilización en clave paisajística. Se valora, en particular, la idoneidad que en muchas ocasiones ofrecen los nombres de lugar como elemento clave en el proceso de comprensión e interpretación de un paisaje: sea en su conjunto, sea en relación con algunos de sus elementos. El artículo tiene un contenido fundamentalmente teórico pero se ilustra con numerosos ejemplos de topónimos con trascendencia geográfica y paisajística en diferentes grados.

\section{Palabras Clave}

Onomástica; toponimia; nombre de lugar; Geografía; paisaje; etimología.

Fecha de recepción: 28 de noviembre de 2019 Fecha de aceptación: 5 de diciembre de 2019

\section{Abstract}

The possibilities of understanding toponyms from a geographical perspective, and especially as a tool for landscape analysis are explored in this article. Our departing point is the premise that the toponym, or place-name, is a concept of plural nature that integrates three dimensions: one, linguistic; another, geographical, and the third, historical. On this basis, the fundamental lines of the use of place-names in landscape are raised. In particular, the suitability offered by toponymy as a key element in the process of analysis and interpretation of a landscape is valued: at a general scale, or in relation to some of its elements. Although the article is essentially conceived as a theoretical reflection, we introduce numerous examples of place-names with relevant geographical significance.

\section{KeYwords}

Onomastics; toponymy; place-name; Geography; landscape; etymology. 



\section{INTRODUCCIÓN}

El propósito fundamental de este artículo es profundizar en el estudio de la interacción entre toponimia y paisaje, centrándonos específicamente en cuestiones de orden teórico y metodológico. Tratamos, en este sentido, de continuar la línea de reflexión que emprendimos dos décadas atrás con nuestra tesis doctoral (Tort, 1999), y que hemos desarrollado desde entonces a través de aproximaciones sucesivas que han tratado de explorar la dimensión geográfica de la toponimia en sus múltiples facetas y a diferentes niveles y escalas de análisis. ${ }^{1}$

El artículo se organiza, más allá del presente apartado introductorio, en un epígrafe de contextualización temática ("La toponimia como disciplina de síntesis") en el que trazamos el marco general de referencia, en un sentido disciplinar, y en otro epígrafe, más extenso ("El problema metodológico"), que constituye de hecho su columna vertebral. En él abordamos, a través de cinco subapartados, diferentes cuestiones de método (o relacionadas con el proceso de construcción de dicho método) que tienen relevancia a efectos de nuestro artículo. Es decir: la relación entre la etimología y la onomástica, el papel histórico de Josep Balari en la introducción de una determinada metodología, la diferenciación entre etimología y etiología de los topónimos, las interacciones entre la geografía y la toponimia, y, finalmente, la propuesta de un "método geográfico" (fundado en tres bases o principios) para la investigación toponímica. Concluimos el artículo con una breve recapitulación o apunte final.

Subrayaremos también, en el contexto de esta introducción, que la consideración del paisaje -concepto que, en general, entendemos en un sentido amplio-, es constante a lo largo del artículo aunque no siempre sea visible o explícita. Partimos de la base, respecto de esta cuestión, que la "conexión" entre el paisaje y el nombre de lugar opera a diferentes grados o niveles y, en consecuencia, a veces puede resultar difícil de delimitar o discernir (e incluso, en ocasiones, ofrecer una apariencia extremadamente sutil). Por este motivo hemos creído imprescindible, en nuestra argumentación general, hacer un énfasis particular en las interacciones entre geografí y toponimia -entendidas como fundamento epistemológico de la referida "conexión" entre nombres y paisajes.

1 Véase, al final, la bibliografía. Las referencias que hemos incorporado en ella, relacionadas con la referida tesis doctoral, tratan de dar cuenta del amplio abanico de temas de estudio que se puede derivar de un enfoque específicamente geográfico de la toponimia. 


\section{LA TOPONIMIA COMO DISCIPLINA DE SÍNTESIS}

La toponimia, entendida genéricamente como la rama de la onomástica que estudia los topónimos (Menéndez Pidal, 1952; Poirier, 1982; Moreu-Rey, 1982; Amigó, 1989; Moran, 1996), ha sido conceptuada por una gran parte de sus investigadores como un ámbito científico de confluencia: es decir, como una disciplina que no se puede adscribir a un campo de conocimiento estricto y cerrado, sino que, por su naturaleza peculiar, puede ser abordada de una manera fructífera y complementaria desde una gran diversidad de perspectivas. Se puede afirmar que la toponimia implica un número considerable de materias, pero las integra no de una manera directa o jerarquizada sino más bien de forma indirecta u horizontal; por este motivo nos atrevemos a calificarla, siguiendo a Morin (2001), como un conocimiento interdisciplinario. Es decir, un ámbito del saber que se imbrica y se interrelaciona con múltiples conocimientos sin confundirse, sin embargo, con ninguno de ellos. En virtud de esta interdisciplinariedad, la relación que, en el terreno de los hechos, queda establecida entre la toponimia y la diversidad de materias que confluyen en su estudio no es tanto de competencia como de cooperación instrumental. Dicho de otro modo: a la hora de estudiar el sentido y el significado de los nombres cualquier aproximación analítica puede ser útil, proceda de donde proceda, si sirve para aportar claridad a la cuestión que nos proponemos descifrar.

En general, los tratadistas, al abordar la definición y el alcance de la toponimia, se han referido de manera específica a su naturaleza interdisciplinaria; unas veces haciendo énfasis en las materias que tienen una mayor relación con los nombres, y otras haciendo hincapié en la importancia que puede llegar a representar una determinada perspectiva de análisis. Poirier (1965), por ejemplo, habla de los tres grandes bloques de "ciencias auxiliares de la toponimia" que son, según su criterio, la historia, la geografía y la lingüística (concretamente, la dialectología y la fonética). Dauzat, en cambio, incide en particular en la vertiente psicológica y sociológica cuando señala que "esta ciencia [la toponimia] constituye de entrada un capítulo precioso de psicología social. Al mostrarnos cómo se han designado, siguiendo las épocas y los medios, las villas y los pueblos, las propiedades y los campos, los ríos y las montańas, nos hace comprender mejor el alma popular, sus tendencias místicas o realistas, sus medios de expresión" (Dauzat, 1971: 9). A su vez Querol defiende, con argumentos fundados en la propia naturaleza de la disciplina, la necesidad de unas actitudes epistemológicas explícitamente abiertas. Y es que, para él, "la toponimia estudia un material que contiene tantas informaciones que pueden existir innumerables maneras de recuperarlas, y ninguna de ellas ha de desterrar a las otras; así, se deja la puerta abierta a posibilidades que ni se nos habrían ocurrido y que desde otros puntos de vista son de lo más evidente" (Querol, 1995: 65). 
Por su parte, Moreu-Rey en Els nostres noms de lloc, y Dorion, en Les relations entre la toponymie et les autres sciences humaines, dos textos relacionados de una manera significativa con la cuestión que nos ocupa, proponen una caracterización amplia del objeto y el alcance de la toponimia. Una caracterización planteada desde dos perspectivas diferentes, pero convergentes en cuanto a su sentido esencial:

"La toponimia pertenece a las llamadas ciencias humanas, como lo son las diferentes ramas de la historia, la historia de la economía y de las instituciones, la sociología y la antropología cultural, la geografía humana, la lingüística y la filología (...). La toponimia utiliza básicamente los servicios de otras tres ciencias: la historia, la lingüística y la geografía, pero tiene que recurrir también a menudo a auxilios adicionales: la epigrafía y la arqueología, la archivística y la paleografía, la etnografía y el folklore, la psicología social, la topografía, la botánica... Inversamente, la toponimia ayuda y ayudará cada día más a estas ciencias. Ya es considerada como uno de los auxiliares más útiles a la investigación humana. Poco a poco, tanto la toponimia en particular como la onomástica en general, han rebasado el estadio infantil donde se las quería mantener. Los estudios onomásticos en nuestro país no habían pasado, salvando tímidas incursiones, de la etapa atomística, o, en todo caso, simplemente taxonómica y clasificatoria: búsqueda de etimologías individuales, inclusión de topónimos en períodos lingüísticos o históricos. (...) Parece llegado el momento de trascender al grado superior de madurez, donde la toponimia y la onomástica pueden ser consideradas como dedicaciones mayores de edad entre las ciencias humanas, y no como sirvientes pobres de la filología o la etimología."” (Moreu-Rey, 1982: 11)

"Recordemos en primer lugar que la toponimia, como numerosas ciencias humanas, se inscribe dentro de la doble dimensión del espacio (la función toponímica) y del tiempo (la memoria toponímica). La toponimia tiene, pues, una relación esencial con la geografía (los nombres de lugar son el vocabulario propio de esta ciencia) y con la historia (en la medida en que los nombres se convierten en el testimonio, más allá del tiempo, de una determinada relación hombre-lugar). El nombre de lugar es un signo lingüístico y, como tal, interesa a la semiología; es la expresión de la percepción de un comportamiento que implica la psicología, sobre todo la psicología

2 Original en catalán. La traducción es nuestra. 
social. Finalmente, el análisis morfológico o semántico del nombre, tanto en lo que respecta a su origen como a su evolución posterior, es cosa de la lingüística y de la psicolingüística, mientras que el análisis sintético o sinóptico de grandes contingentes de nombres queda para el campo de la sociolingüística y puede desembocar en estudios propiamente sociológicos."”3 (Dorion, 1984: 103)

\section{El problema metodológico}

\subsection{APUNTE PRELIMINAR: EL DIFÍCIL DESLINDE ENTRE LA INVESTIGACIÓN ETIMOLOGICA Y LA INVESTIGACIÓN ONOMÁSTICA.}

El desarrollo relativamente reciente de la onomástica (y de la toponimia) como campo de estudio tiene que ver, en buena medida, con la dificultad que para las ciencias lingüísticas ha significado, tradicionalmente, el estudio de la etimología: un concepto que el diccionario define como "origen de las palabras, razón de su existencia, de su significación y de su forma” (RAE, 1984, I: 613) y que, por su complejidad intrínseca, deviene en todas las lenguas del mundo un ámbito abierto a múltiples (y a menudo inextricables) incertezas.

Desde el punto de vista histórico, la ciencia etimológica se desarrolló como rama de la lingüística a partir de mediados del siglo XIX. A propósito de esta ciencia, Benjamin W. Dwight, que es considerado como uno de sus precursores, escribía en 1865 que "en este país [Estados Unidos], así como en Inglaterra y Francia, y en general en todas partes con la excepción de Alemania, el estudio de la etimología vernácula y clásica se encuentra en el mismo estadio grosero y falto de método, propio de los descubrimientos primeros y parciales, en que se encontraban tanto la química como la geología medio siglo atrás" (Dwight, 1865: 277). Dwight hacía esta afirmación en Modern Philology: its Discoveries, History and Influence, una obra de gran significación en su época (y que en nuestro contexto cultural fue dada a conocer por Balari), la tercera parte de la cual llevaba el significativo título de "The science of Etymology". En ella, el autor hacía una defensa explícita de la ciencia etimológica, que calificaba como "poesía fósil, filosofía e historia combinadas" (p. 338), y de la que reivindica su valor peculiar en el "entrenamiento de la mente para la comunicación y la comunión con otras mentes". Por todo ello, concluía Dwight, la etimología se acaba configurando como una "química del lenguaje"(Dwight, 1865: 345).

A pesar de la evolución experimentada por la ciencia etimológica en los últimos ciento cincuenta años, correlativa en parte al desarrollo de las diversas subdisciplinas de la lingüística, la problemática permanentemente irresuelta de tener que trabajar con estratos lingüísticos arcaicos o fósiles provoca que la

3 Original en francés. La traducción es nuestra. 
investigación toponomástica de base filológica se mueva, en gran parte, dentro de "un lenguaje lleno de inseguridades, de propuestas poco fundadas y de especulaciones constantes" (Duarte, 1981: 79). A esto mismo se refería uno de los grandes especialistas en etimología dentro de las lenguas romances, Joan Coromines $^{4}$, cuando en 1973 señalaba que "hay que reconocer, verdaderamente, que el desarrollo de la toponomástica en el mundo ha avanzado menos de lo que se esperaba a principios de este siglo" (Corominas, 1973: 193). En vista de la incertidumbre metodológica que se cierne permanentemente sobre el etimologista, el propio profesor Coromines propone, como premisa básica para la investigación etimológica en toponimia, la diversificación de los criterios de análisis. En este sentido, en Tópica Hespérica enumera, como criterios de referencia, los siguientes: a) la determinación del área geográfica de las diferentes lenguas que han existido o que existen en un determinado territorio; b) las terminaciones características de las palabras; c) las leyes gramaticales; d) la fonética histórica; e) las formas documentales; f) los fonemas característicos; g) la comparación semántica; h) los datos geográficos, y, finalmente, i) los datos históricos (Corominas, 1972, I: 130-156).

A pesar de reconocer la precisión y el rigor en los que se basa la propuesta metodológica de Coromines, hay que subrayar que las prevenciones de método no resuelven, sin embargo, la problemática inherente al estudio etimológico; es decir, la dificultad de tener que trabajar con "fósiles" o con "reliquias" de la lengua (esto es: con palabras que han perdido virtualidad significativa en relación con el sistema lingüístico vigente en un momento dado). Al haberse perdido la noción precisa del referente (o sea, su "entidad significativa" plena), es evidente que el análisis etimológico siempre necesitará recurrir, en una determinada medida, a la especulación (es decir, deberá formular hipótesis en múltiples direcciones y a través un amplio intervalo de tiempo). Y, en opinión nuestra, la conciencia de esta incertidumbre, de esta "inevitabilidad" de la especulación, ha llevado a algunos lingüistas a formular una propuesta metodológica diferenciada: el estudio de la etiología de los topónimos. Pero antes de referirnos a ella trazaremos un breve apunte sobre una contribución pionera en la investigación etimológica en el ámbito hispánico: la que realizará desde la Universidad de Barcelona, a finales del siglo XIX, Josep Balari. Una contribución que supondrá de hecho el arranque, en nuestro ámbito geográfico y en el conjunto de Espańa, de los estudios toponomásticos modernos; esto es, concebidos sobre una base científica.

4 A lo largo del artículo se podrá observar que se hace mención de este autor, a veces, con la grafía Corominas (y no con la terminación en -es que sería, en propiedad, la que corresponde). No se trata de un error, sino una consecuencia del hecho que, durante el régimen de Franco, el uso de la lengua catalana se encontraba oficialmente proscrito incluso a un nivel tan íntimo y personal como la grafía de los nombres y apellidos. 


\subsection{CONSIDERACIÓN PARTICULAR DE LA APORTACIÓN DE BALARI}

Por su carácter pionero e innovador, la obra de Josep Balari i Jovany (18441904) puede ser considerada como el inicio de los estudios etimológicos y toponímicos en Cataluña y en el conjunto de España (Tort, 2008). Su primer trabajo en esta línea es una monografía cuyo título resulta, por sí mismo, altamente expresivo: Orografía, estudio etimológico de los nombres de cimas o cumbres de montes (Balari, 1877); pero más significativo, respecto a este autor, es aludir a su obra fundamental: Orígenes históricos de Cataluña (Balari, 1899). Se trata de una vasta investigación histórica sobre la génesis de Cataluña, fundada en documentación de la época condal (concretamente, de los siglos IX a XII). La originalidad del trabajo, sin embargo, no radica tanto en su concepción genérica de "obra histórica" como en su organización metodológica y, en definitiva, en su materialización concreta. En este sentido -y aquí encontramos la gran novedad de la fórmula de trabajo adoptada por Balari-, el autor hace un análisis sistemático de todo el aparato documental de que dispone, con el propósito de descubrir la etimología de los nombres de lugar, poner estos nombres en relación con el territorio al que se refieren y, en última instancia, interpretarlos como "claves explicativas" del proceso histórico medieval catalán.

Propiamente, la obra está dividida en cuatro grandes apartados ("Geografía", "Reconquista", "Feudalismo" y "Civilización"), el primero de los cuales es el más extenso (comprende unas 270 páginas, sobre un total de 733). Llama la atención que sea el apartado relativo al territorio (y con el título, precisamente, de "Geografía"), el protagonista. Al respecto, creemos que vale la pena reproducir unas consideraciones preliminares del propio Balari:

"En los Orígenes históricos de Cataluña ocupa un lugar preferente la geografía de esta región, que en su nomenclatura 'geográfica' tiene uno de los fundamentos principales de su historia. Los nombres geográficos son vestigios que han quedado como testimonio de los más antiguos pobladores de Cataluña, por lo que su estudio ofrece también interés de actualidad. Los documentos más antiguos, que contienen nombres de lugar en su forma original o en la forma más cercana a su origen, son los únicos monumentos que deben servir de base al estudio geográfico, porque la nomenclatura actual presenta más o menos alteradas formas primitivas." (Balari, 1899: 19)

Más adelante, el autor amplía la "declaración de principios" transcrita con una reflexión complementaria:

"El estudio geográfico e histórico de Cataluña tiene una importancia verdadera, en la medida en que contribuye a poner de manifiesto los orígenes históricos de esta región. Región que ha sido habitada por pueblos diversos y que hablaban lenguas diferentes, 
como lo atestiguan los nombres de lugar; nombres de lugar las formas actuales de los cuales proceden de otras formas primitivas, que han sido conservadas en su estructura más o menos original por los documentos antiguos" (Balari, 1899: 19).

Desde el punto de vista metodológico llama la atención la organización interna de los capítulos, basada en la idea de la "afinidad semántica" de los términos que trata. Por ejemplo, en el capítulo tercero, que hace referencia a términos de carácter orográfico, las palabras que analiza (objeto, cada una de ellas, de un epígrafe específico) son las siguientes: ${ }^{5}$ puig [pico]; pujal, pujol, pujolar [derivados de puig]; roca; quer, quera [variantes de roca]; cot [canto]; codina, còdol, pera [variantes de cot]; mont [montaña] montells [variante de mont]; montaña, montañola; pena [peña]; penella [diminutivo de pena]; Penedés, Cervera, Puigcerver; serra [sierra]; serrat [variante de serra]; Serradell.

Para completar el análisis, reproducimos a continuación el epígrafe relativo al término serra como muestra del tratamiento general que aplica el autor en cada una de las palabras o topónimos estudiados: ${ }^{6}$

"Serra. Esta palabra procede del bajo latín serrum y significa 'cordillera de montes o peñascos cortados'. Varios son los lugares conocidos con el nombre de serra. Un documento del año 1031 hace mención del término de Sancti martini ad ipsa serra, que es el lugar de Sant Martí Saserras del partido de Figueras en la provincia de Gerona. A legua y media de la Bisbal, en la misma provincia, hay un lugar llamado Serra. En una escritura del ańo 1068 se nombra Collsabadell, en el Vallés, como situación en la parroquia Sancte marie de ipsa serra. Sant Feliu de Sa serra es un lugar que dista cuatro leguas y media de Vich, y la Serra es una aldea situada a legua y media de Valls en la provincia de Tarragona". (Balari, 1899: 77)

A nuestro juicio, uno de los méritos que hay que reconocer al autor, y que es perceptible en el tenor del epígrafe que hemos transcrito, es su voluntad de asociación y de interrelación de conceptos, de nombres y de lugares. En Balari hay un planteamiento de estudio de los nombres no enciclopedista, o meramente historicista, sino una pretensión esencial de analizarlos de una forma integrada, partiendo de una documentación sólida y haciendo un uso constante del método comparativo. Y, en último término, tomando los documentos no como el objeto final de su investigación, sino poniéndolos al servicio de una "interpretación

5 Las transcribimos respetando la ortografía del original.

6 Reproducimos aquí, literalmente, el texto original.

7 La cursiva es del autor. 
territorial" de la historia de Cataluña. Seguramente, la originalidad y el carácter innovador del método de trabajo del autor fueron una de las claves del prestigio y el renombre alcanzados por la obra, que devino, a partir de ahí, un referente obligado en la historia de la onomástica peninsular.

\subsection{ETIMOLOGÍA Y ETIOLOGÍA DE LOS TOPÓNIMOS}

Moreu-Rey, en un trabajo de 1995, definía la etiología de un topónimo como el estudio de las causas y las circunstancias que lo han originado; concretamente, "el examen de los factores que han permitido, favorecido u obligado la generación de un nombre de lugar" (Moreu-Rey, 1995: 47). Se trata, según el propio autor, de un punto de vista que nos aproxima a la naturaleza del topónimo. Profundizando en esta idea inicial, otro autor, Xavier Terrado, señala que la etiología quiere averiguar las causas que han motivado el nacimiento de un nombre de lugar, mientras que la etimología pretende más bien conectar el nombre con otros nombres preexistentes (Terrado, 1994: 59-60). A fin de ilustrar la argumentación con ejemplos, Terrado señala el caso del topónimo Sant Martí, cuya difusión está muy ligada a la particular devoción que se tenía por este caballero-obispo en los siglos medievales; o bien el caso de los topónimos Miralles y Espills, que según el mismo autor no se pueden explicar cuando se ignora la importancia que tenían las señales ópticas (o lumínicas), durante la Edad Media, en los territorios fronterizos. Para Terrado, la consideración de factores como los mencionados no es tanto el objeto específico de la etimología como de la etiología, entendida esta segunda perspectiva, sin embargo, en un sentido complementario de la primera.

No dudamos que el estudio de la etiología de los nombres puede significar una gran ventaja de cara a profundizar en su etimología. Ahora bien, sin negar la verosimilitud de este planteamiento, quisiéramos subrayar un aspecto que tiene relación con el trasfondo de estas cuestiones y que creemos que no siempre es tenido debidamente en cuenta: la conveniencia de implicar, de una forma conjunta, las tres grandes perspectivas de estudio que, en un momento dado, convergen en la temática que nos ocupa. Esto es, la que hace hincapié en la materialidad del nombre, o filológica; la relacionada específicamente con el tiempo, o histórica, y la que toma como eje vertebrador el espacio, o geográfica.

En la práctica, las tres perspectivas se interrelacionan y presentan un grado elevado de interdependencia. Es cierto que cada una de ellas se sitúa en una dimensión epistemológica propia y hace uso de unos aparatos metodológicos y de investigación diferenciados; pero esto no impide que su pretensión final (y convergente) sea, en relación con un nombre dado, el establecimiento o el descubrimiento de su "significación global" (una significación que equivaldría, por así decirlo, a la "suma” de la etiología y la etimología de este nombre). 
3.4. INTERACCIONES ENTRE LA GEOGRAFIA Y LA TOPONIMIA: LA APORTACIÓN DE UN PUNTO DE VISTA CENTRADO ESPECÍFICAMENTE EN EL ESPACIO

Nos proponemos completar las consideraciones teóricas y metodológicas hechas hasta aquí con una reflexión sobre el papel que puede corresponder a la perspectiva geográfica en relación con la toponimia. Partimos de la premisa que, en nuestra opinión, hay un desconocimiento bastante generalizado de las potencialidades propias del punto de vista geográfico al abordar la interrelación entre "territorio" y "lengua". Observémoslo, por ejemplo, en el texto que transcribimos a continuación. Se trata de un texto escrito por un lingüista, Carles Duarte, en el que se hace referencia a la problemática que representa, para el etimologista, desconocer el contenido semántico del nombre de lugar:

"La toponomástica, sin embargo, no puede a menudo contar con la ayuda del contenido semántico del nombre de lugar, que desconocemos. He aquí una dificultad importante. Si, por ejemplo, nosotros resolviéramos el análisis toponímico del nombre Naranco (conocido pico de los Picos de Europa) afirmando que, de acuerdo con una cierta tendencia moderna de llamarlo Naranjo, es un derivado de 'naranja', cometeríamos un error considerable. Porque, como nos aclaró el profesor Coromines, la verdadera etimología de la palabra es *NERANKOS, 'gigante', del indoeuropeo hispánico, formado sobre la base indoeuropea común ner-, hombre, varón fuerte, potente, heroico"'. (Duarte, 1981: 82)

No compartimos, por nuestra parte, que la toponomástica no pueda contar más que excepcionalmente con "la ayuda del contenido semántico del nombre de lugar". Este supuesto puede ser excepcional para el estudioso de los nombres en una perspectiva diacrónica (o sea, para el interesado en el origen remoto de un nombre dado), pero no para la persona que se enfrenta con los nombres como entidades lingüísticas referidas al momento presente; para esta persona, cualquier nombre de lugar vigente tiene contenido semántico; es decir, un significado que se corresponde con la concreción en el espacio que en este momento tiene el nombre en cuestión. "Significado" y "dimensión espacial" (o "trascendencia espacial") serían, desde este punto de vista, expresiones equivalentes. Estudiar la dimensión espacial de un nombre de lugar querría decir, desde esta óptica, analizar la individualidad de este espacio, su "diferenciación específica" respecto al resto del espacio. El único requisito previo para el análisis del "espacio individualizado" sería la explicitación de la coordenada temporal: es decir, la determinación del momento al que se hace referencia. Para la etimologista, este "momento" es un punto del tiempo remoto ( $y$ difícilmente determinable): el instante del origen de

8 Original en catalán. La traducción es nuestra. 
la palabra. Para el geógrafo, en cambio, el momento de referencia es más bien el "ahora", el instante presente.

Al hilo de este razonamiento podemos concluir que el espacio tiene, para el etimologista y para el geógrafo, una dimensión temporal diferente. Al primero le interesa el espacio como situado en un momento del tiempo más o menos lejano: es el espacio que le permitirá descubrir la razón de ser originaria de la palabra, su génesis. Al segundo, en cambio, le interesa el espacio como realidad actual, perceptible, evidente (o sea, y haciendo salvedad de la tautología, como "realidad real"). Ambos espacios pueden coincidir o no: es muy normal que, a lo largo del tiempo, la entidad significativa, el "espacio individualizado", a que hace referencia un nombre de lugar, cambie. Aunque no coincidan, ambos espacios interesan a los dos estudiosos mencionados; eso sí, desde perspectivas diferentes: al etimologista le interesa el "espacio individualizado" actual, a fin de tener unos puntos de referencia que, a pesar de ser actuales, puedan dar luz a su inmersión en el pasado. Al geógrafo le interesa el "espacio individualizado" pretérito: su interpretación del presente siempre será más cuidadosa y precisa cuanto más ricos y variados sean los datos de que se disponga referidos al pasado. Por eso podemos decir que una perspectiva y la otra se imbrican, se interrelacionan y se fecundan mutuamente. De ahí que, volviendo al ejemplo de referencia, sea necesario que el estudioso de la etimología de la palabra Naranco se fije no sólo en la raíz remota del nombre: valdrá la pena, también, que observe la fisonomía, las características, la profunda individualidad de esta montaña. Será entonces cuando descubrirá que, en relación con todas las demás montańas de alrededor, el Naranco se presenta como un verdadero "gigante": bastión de roca aislado que se levanta sobre la pequeña aldea de montaña de Bulnes. Seguramente, y desde la perspectiva estricta del espacio, una de las montañas más bien "individualizadas" y "diferenciadas", respecto a su entorno inmediato, de toda la Cordillera Cantábrica.

Vale la pena recordar aquí, en el contexto de la reflexión anterior sobre la interacción entre "lengua" y "territorio", que la profunda imbricación entre un concepto y otro ha sido reiteradamente señalada, en el ámbito de la lengua catalana, por algunos de sus investigadores modernos más destacados; en particular, por Joan Coromines. Nos parece de interés transcribir aquí un fragmento de un trabajo de este autor donde queda bien explicitada la necesidad, por parte del investigador, de trabajar en estas cuestiones desde una óptica sensible a las interrelaciones geográfico-lingüísticas:

"A menudo el aspecto del lugar nos guiará hacia el significado. No puede ser casual que todos los lugares que citamos a continuación se encuentren junto a un gran precipicio o acantilado: l'Espà (cerca de Gósol, en el Berguedà), Sant Salvador de les Espases (cerca de Olesa de Montserrat, en el Baix Llobregat), la Torre de l'Espada (Centelles, Osona), Castellsespasa (Bassegoda, Alt Empordà), Espades (alto 
Berguedà), barranco de l'Espada (Ports de Tortosa), Coma-l'espada (el pico más alto del valle de Sant Nicolau, confluente con el valle de Boí), el antiguo nombre de Spatamala (Torelló, Osona), la serra d'Espadà, cerca de Onda; es, pues, una conclusión prudente creer que el latín SPATHA, del que conocemos en catalán las variantes espasa, espaa y espada, tuvo el mismo sentido que su derivado espadat". ' (Coromines, 1965, t. I: 18)

\subsection{UN MÉTODO GEOGRÁFICO PARA LA INVESTIGACIÓN TOPONÍMICA: LOS PRINCIPIOS}

\section{DE TRANSPARENCIA, DE EXCEPCIONALIDAD Y DE SIGNIFICATIVIDAD TERRITORIAL}

Los argumentos desarrollados hasta aquí han tenido un componente en gran parte teórico y reflexivo. En general, nuestro objetivo ha sido hacer patente que el parámetro territorio es esencial en una comprensión amplia de la noción de nombre de lugar, y que las aptitudes y los puntos de vista del geógrafo -en calidad de "experto en territorio", como a priori se le podría definir- pueden ser particularmente útiles en cualquier investigación toponímica. Ahora pasaremos a un terreno más práctico. Trataremos, concretamente, de explicar lo que en opinión nuestra son tres principios toponímicos básicos: el de transparencia, el de excepcionalidad y el de significatividad territorial. ${ }^{10}$ Tres principios que, en su esencia, tienen bastante que ver con algunas consideraciones que hemos ido planteando a lo largo del artículo. Y que, por otra parte, y de acuerdo con lo que sugerimos en el enunciado de este epígrafe, pensamos que pueden constituir la base de un método geográfico para la investigación toponímica. Un método que aquí no desarrollamos en detalle, por razones de espacio. Pero que, en el plano de la idea básica, creemos que puede quedar en los siguientes párrafos suficientemente delineado.

\section{a) Principio de transparencia}

En su formulación más simple, este principio apunta a la idea de que, con carácter general, la toponimia viva de un territorio determinado tiende a ser en gran parte "transparente". Es decir, que un número importante -aunque en proporción variable, de unos lugares a otros- de los topónimos utilizados en un ámbito geográfico dado puede ser interpretado en su sentido recto -o sea, sin necesidad de recurrir a referencias etimológicas- por parte del común de los hablantes. A título de ejemplo, y en el dominio lingüístico del castellano, algunos nombres

9 Original en catalán. La traducción, adaptada, es nuestra.

10 Además de los tres principios tratados aquí, de transparencia, de excepcionalidad y de significatividad territorial, hemos abordado en otras ocasiones (Tort \& Sancho, 2014) tres principios más que los complementan: el de analogía, el de persistencia y el de interferencia reciproca entre toponimia $y$ antroponimia. Nos queda por hacer, como posibilidad de futuro, una sistematización de conjunto de lo que denominamos "principios toponímicos". 
que ejemplificarían el principio -siempre y cuando no se hubiera producido la circunstancia conocida como cambio semántico- son los del tipo siguiente: fuente del Caño, camino de la Fuente, calle Ancha, torrente Seco, barrio de la Estación, lago de la Hondonada, plaza del Mercado, cementerio Nuevo, etcétera. Es decir, nombres de los que se puede deducir, a priori, una cierta "literalidad" (o, incluso, en ocasiones, "banalidad") en su proceso de conformación. Pero que, sin duda, más allá de la simplicidad de su apariencia, presentan por regla general la virtud de constituir el reflejo de una plena concordancia, en el plano real, entre nombre y significado.

En la práctica, en la base del principio de transparencia, en los términos en que lo hemos presentado, hay un hecho reiteradamente señalado por los lingüistas: que el componente fundamental de la toponimia de cualquier territorio del mundo es el léxico común de la lengua de dicho territorio. Y más allá de la situación descrita suele suceder, como ya hemos señalado con anterioridad, que la investigación etimológica sobre la toponimia de un ámbito geográfico dado se centre tan solo en un determinado grupo de topónimos: es decir, los que tienen más interés desde el punto de vista etimológico -que generalmente son los de sentido más opaco y más impenetrable para el común de los hablantes.

Aunque no tenemos constancia de que el principio de transparencia haya sido formulado como tal desde tiempo atrás, sí es posible encontrar un cierto "eco" del mismo en referencias varias de autores conocidos. Así, al inicio de lo que es una obra clásica en onomástica catalana, Els nostres noms de lloc, su autor afirma: "existe un gran número de nombres de lugar cuyo sentido es claro y comprensible" (Moreu-Rey, 1982: 12). Terrado, a su vez, en un estudio de metodología toponímica, nos recuerda que "la mayor parte de nuestros topónimos tiene un étimo dentro mismo del catalán, del que ahora se habla o del que se habló años o siglos atrás" (Terrado, 1999). Coromines, por su parte, sintetiza la cuestión en la cita del último párrafo que hemos transcrito de este autor: "a menudo el aspecto del lugar nos guiará hacia el significado". Una manera, pues, indirecta pero expresiva de referirse a los múltiples topónimos existentes de tipo transparente, asociando la cualidad de transparencia a la particular fisonomía geográfica del lugar en cuestión. La afirmación de Coromines puede ser interpretada, también, como una "declaración de principios" sobre lo que podríamos identificar como connivencia o complicidad esencial entre toponimia y geografía. ${ }^{11}$

b) Principio de excepcionalidad

Conocido más bien como "principio de negatividad relativa", fue formulado por primera vez por el toponimista ruso F. P. Savarensky (Dorion y Poirier, 1975).

11 Hemos llevado a cabo una consideración de detalle acerca de la dimensión territorial (o geográfica) de la obra de Joan Coromines en Tort (2007). 
Podemos resumirlo como un tipo particular de comportamiento toponímico en el que los nombres de lugar, en contextos determinados, tienden a reflejar primero las características excepcionales del entorno donde se insertan que no las características típicas o más fácilmente perceptibles. Refiriéndose a este principio, los dos autores citados señalan que determinados nombres "atestiguan, por el hecho mismo de su ocurrencia, la carencia relativa o la rareza del fenómeno al que hacen referencia”. Es el caso, según señalan, de la elevada frecuencia de los nombres alusivos al agua en las regiones más áridas de África del norte o de Asia central. El geógrafo Henri Dorion, por su parte, amplía esta consideración en otro texto, del que extractamos un fragmento particularmente expresivo:

"Lo excepcional excita más la memoria que lo típico, por lo que cualquier persona tendrá tendencia, de una manera más natural, a inscribir en su recuerdo -o en un nombre que conservará este recuerdo- una sorpresa antes que una circunstancia banal... En ningún sitio como en el Sahara se encuentran tantos nombres formados a partir de raíces que aluden al agua. Lo que es extraño y vital merece ser consignado, localizado, puesto de relieve, señalizado -como marcado con balizas"12 (Dorion, 1989: 4).

Por nuestra parte, hemos tenido ocasión de verificar el cumplimiento del principio de excepcionalidad en la toponimia de los municipios montańosos de la comarca del Baix Camp (Tarragona). Concretamente en relación con un concepto orográfico, los llanos, y otro hidrográfico, las fuentes: en los dos casos se da la circunstancia (aparentemente paradójica) de que la aparición de una toponimia de detalle alusiva a la presencia de "zonas llanas", por un lado, y de surgencias naturales, o "fuentes", por otro, se produce con mucha mayor profusión en los municipios donde tales elementos del medio físico destacan por su escasez relativa (como son los de la orla montañosa de la comarca, cuyo medio destaca por su carácter abrupto y por la escasez de recursos hidráulicos), que no en los municipios del centro y del sur de la comarca (de un carácter eminentemente llano y donde el agua, superficial o subterránea, tiene por lo general una presencia importante (Tort, 1999).

c) Principio de significatividad territorial

El principio que hemos denominado de "significatividad territorial" (Tort, 2003) se sitúa a medio camino de los dos principios que acabamos de describir. De hecho, su lógica se sitúa en el punto intermedio de los otros dos: apunta, concretamente, a los hechos que se pueden considerarse como significativos desde la perspectiva territorial. Y que se ubican a medio camino entre la "habitualidad"

12 Original en francés. La traducción es nuestra. 
(inherente, en la práctica, a los hechos normales y reiterados a los que responde el principio de transparencia) y la "singularidad" (o comportamiento único e inhabitual, propio de los hechos que justifican el principio de excepcionalidad). En este contexto, "lo territorialmente significativo", según nuestro criterio, sería un aspecto de la geografía de una determinada región que se muestre de alguna manera destacado o relevante respecto a otros aspectos -aunque la percepción de esta relevancia quede supeditada, en numerosas ocasiones, a un conocimiento específico, por parte del observador, del medio geográfico al que se está aludiendo.

Un ejemplo toponímico mencionado por Paul Vidal de la Blache nos será útil para ilustrar la idea de la "significatividad" del territorio en los términos expresados. Explica este autor, en un texto en el que plantea una serie de analogías entre topónimos, que en el extremo occidental del Macizo Central francés hay un territorio conocido con el nombre de Terres Froides, mientras que un poco más al oeste el país es conocido con el nombre de Terres Chaudes. Son dos territorios adyacentes y más bien llanos, poco diferenciados desde el punto de vista físico. Frente a una interpretación literal de los topónimos, que lleva a pensar en una diferencia de temperatura importante entre un ámbito geográfico y el otro, la realidad de los hechos, según Vidal, es que la diferencia no es de clima, sino de naturaleza del terreno. El nombre de Terres Froides se explica porque allí el sustrato es impermeable; el agua se estanca en el lugar dando origen a humedad y niebla. En cambio, en las denominadas Terres Chaudes (no demasiado alejadas, por otra parte, de las Terres Froides) el terreno es calcáreo, por lo que las aguas se infiltran y su fisonomía externa se mantiene seca. No es extraño, pues, que el ambiente del lugar lleve a hablar de "tierras frías" en el primer caso, y de "tierras cálidas" en el segundo. Ahora bien: la percepción de esta diferencia, territorialmente significativa, sólo es posible mediante un conocimiento expreso de la geografía del lugar. Un conocimiento que tiene que ver directamente con un método fundamental para el estudio del territorio: es decir, la observación.

A escala del territorio catalán no es difícil encontrar ejemplos en un sentido comparable. Ejemplos que ponen de manifiesto, al fin y al cabo, que a través de este principio podemos disponer de elementos de juicio complementarios (o "añadidos") a la hora de interpretar determinados topónimos. Tres casos nos parecen, al respecto, claramente ilustrativos. En primer lugar, el de Montsec, nombre aplicado a una de las sierras más importantes del Prepirineo, en el que la alusión a la "sequedad" no nos ha de extrañar si se tiene presente la litología caliza de la montaña y la consiguiente ausencia en ella de corrientes de agua superficiales. En segundo lugar, el de Montseny, nombre documentado como Montis Signi en 848 e interpretado etimológicamente (y con fundamento de causa) como la "montaña señal" (Coromines, $O C$, V: 381). Se trata de un nombre 
que apunta a una cualidad particularmente significativa del macizo, cuando se considera su posición relativa dentro de la cordillera prelitoral catalana: es decir, su visualidad. Y, finalmente, el caso de Flix, nombre de un núcleo de población de la comarca de Ribera d'Ebre, documentado Flexio en 1153 y etimológicamente vinculado al latín flexus, "curvatura" o "sinuosidad" (Coromines, OC, IV: 229). La circunstancia de que el pueblo esté geográficamente emplazado sobre un estrecho meandro del río Ebro - un accidente orográfico bastante excepcional en el tramo catalán de este río- cabe considerarla un argumento de una gran significatividad, según nuestra opinión, en el momento originario de la atribución del nombre al lugar.

\section{Apunte final}

Hemos podido comprobar, a lo largo del artículo, que si hay un cualidad que informa todo lo que tiene que ver con la relación entre los topónimos y la geografía (y, dentro de esta última disciplina, con el paisaje), dicha cualidad no puede ser otra que la complejidad. El cruce continuado y persistente, dentro del dominio general de los nombres, entre un vector fundamental de orden espacial con otro de carácter temporal dificulta, por regla general, toda interpretación de los mismos que se funde en criterios lineales o de pura simplicidad. Pero no se trata solo de esta circunstancia: otras, de rango equivalente, se superponen a la propia interacción entre espacio y tiempo, y contribuyen a hacer más difícil la observación y el análisis en el campo general de los nombres geográficos: cuestiones como la concurrencia, en su formación, de lenguas y de materias múltiples y diversas (que nos llevan a hablar con toda razón, en onomástica, de plurilingüismo y de interdisciplinariedad), contribuyen a hacer que el estudioso de este ámbito se encuentre inmerso, constantemente, en el dominio de lo complejo.

En el marco descrito queremos subrayar que, con nuestra reflexión, no hemos pretendido en modo alguno dar cuenta, de un modo expeditivo y global, de las problemáticas apuntadas. Por el contrario: teniendo en cuenta su fondo intangible $y$, a menudo, imposible de objetivar en un sentido absoluto, hemos considerado que un ejercicio de revisión metodológica como el presente tal vez era, en estos momentos, el más oportuno y necesario.

\section{Agradecimientos}

Este trabajo ha sido realizado en el marco del Proyecto de Investigación CSO2015-65787-C6-4-P, del Ministerio de Economía y Competitividad (MINECO/FEDER, UE), y en el seno del Grup de Recerca Ambiental Mediterrània, GRAM, reconocido por la Generalitat de Catalunya (2017SGR1344). 
BiBLIOGRAFÍA

Amigó, R. (1989). Sobre inventaris de noms de lloc. Introducció metodològica. Reus: Edicions del Centre de Lectura.

Balari, J. (1899). Orígenes históricos de Cataluña. Barcelona: Establecimiento Tipográfico de Hijos de Jaime Jepús.

Coromines, J. (1965). Introducció a l'estudi de la toponímia catalana. En Estudis de toponimia catalana, I (pp. 7-30). Barcelona: Barcino.

Corominas, J. (1972). Tópica hespérica. Estudio sobre los antiguos dialectos, el substrato y la toponimia romances. (2 vol.) Madrid: Gredos.

Corominas, J. (1973). Du nouveau sur la toponymie occitane. En Beiträge für Namenforschung, VIII, (pp. 193-308).

Coromines, J. (1983-1991). Diccionari etimologic i complementari de la llengua catalana. (9 vol.). Barcelona: Curial-Caixa de Pensions. Abreviatura: DECLC).

Coromines, J. (1989-1997). Onomasticon Cataloniae. (8 vol.). Barcelona: CurialCaixa de Pensions. (Abreviatura: OnoCat).

Dauzat, A. (1971). La toponymie française. París: Payot.

Duarte, C. (1981). De l'origen dels mots. Barcelona: Indesinenter.

Dorion, H. (1984). Les relations entre la toponymie et les autres sciences sociales. En 450 ans de noms de lieux français en Amerique du Nord. (pp. 103-108). Québec: Les Publicacions du Québec.

Dorion, H. (1989). Où. Conferencia pronunciada en la Universidad Laval (Québec) el 5.12.1989. Manuscrito original.

Dorion, H. (1993). A qui appartient le nom de lieu?. Onomastica Canadiana, 75, $1-10$.

Dorion H. y Poirier, J. (1975). Lexique des termes útiles à l'étude des noms de lieux. Québec: Les Presses de l'Université Laval.

Dwight, B.W. (1865). Modern Philology: its Discoveries, History and Influence. New York: Ch. Scribner.

Menéndez Pidal, R. (1952). Toponimia prerrománica hispana. Madrid: Gredos.

Moreu-Rey, E. (1982). Els nostres noms de lloc. Palma de Mallorca: Moll [1 $1^{\mathrm{a}}$ ed, 1965].

Moreu-Rey, E. (1995). Tipologia toponímica. En V.M. Rosselló Verger; E. Casanova (eds.), Materials de toponimia-I. (pp. 45-52). València: Generalitat Valenciana-Universitat de València.

Moran, J. (1996). Consideracions sobre l'onomàstica. Barcelona: Institut d'Estudis Catalans. 
Morin, E. (2001). La mente bien ordenada. Repensar la reforma. Reformar el pensamiento. Barcelona: Seix Barral.

Poirier, J. (1965). Toponymie. Méthode d'enquête. Québec: Les Presses de l'Université Laval.

Poirier, J. (1982). Regards sur les noms de lieux. Québec: Gouvernement du Québec.

Querol, E. (1995). La metodología en els estudis de toponímia. En V. M. Rosselló y E. Casanova (eds.), Materials de Toponímia-I (pp. 61-74). València: Generalitat Valenciana-Universitat de València.

Real Academia Española. (1984). Diccionario de la lengua española. Madrid: Espasa Calpe [20a edición]. (Abreviatura: RAE), 2 tomos.

Terrado, J. (1999). Metodología de la investigación en toponimia. Zaragoza: edición del autor.

Tort, J. (1999). Els noms de lloc i el territori. Una interpretació geogräfica de la toponimia del Baix Camp. Tesis doctoral, Universitat de Barcelona.

Tort, J. (1999). Algunes reflexions sobre el concepte de topònim. Butlletí Interior de la Societat d'Onomàstica, 77, 59-72.

Tort, J. (2000a). Els noms de lloc i la geografia. La toponímia com a eina per a la conceptualització de l'espai. Butlletí Interior de la Societat d'Onomàstica, 83, $86-98$.

Tort, J. (2000b). La geografia, els noms de lloc i la descripció del territori. En J. F. Mateu y E. Casanova (eds.), Estudis de toponímia valenciana en honor de Vicenç M. Rosselló $i$ Verger (pp. 491-198). València: Denes Editorial.

Tort, J. (2003). A propòsit de la relació entre toponímia i geografia: el principi de significativitat territorial. Butlletí Interior de la Societat d'Onomàstica, 94-95, 675-688.

Tort, J. (2006). Els noms de lloc i el territori. La toponímia des de la geografia. En E. Mallorquí, (coord.), Toponimia, paisatge i cultura. Els noms de lloc des de la lingüistica, la geografia i la història (pp. 69-99). Girona: Associació d'Història Rural de les Comarques Gironines-Universitat de Girona-Documenta Universitària.

Tort, J. (2007). Per a una interpretació geogràfica de l'obra etimològica de Joan Coromines. En E. Casanova y X. Terrado (eds.), Studia in honorem Joan Coromines (pp. 263-287). Lleida: Pagès Editors.

Tort, J. (2008). Sobre el valor geograficotoponímic de l'obra 'Orígenes históricos de Cataluña (1899)', de Josep Balari i Jovany. Revista de Catalunya, 243, 4160 . 
Tort, J. (2010). Some reflections on the relation between toponymy and geography. Onoma. Journal of the International Council of Onomastic Sciences, 45, 253-276.

Tort, J. (2017). Los nombres de lugar, entre el paisaje y el patrimonio. El valle del Ebro como ejemplo. En F. Molinero y J. Tort (coord.), Paisajes patrimoniales de España (pp. 106-127). Madrid: Ministerio de Agricultura, Pesca, Alimentación y Medio Ambiente-Universidad Autónoma de Madrid, tomo I.

Tort J. y Sancho, A. (2014). Toponyms as landscape indicators. En Tort, J. \& Montagut, M. (eds.), Names in daily life. Proceedings of the XXIV ICOS International Congress of Onomastic Sciences (pp. 1987-2016). Barcelona: Generalitat de Catalunya. Appendix, section 8.

Vidal de la Blache, P. (1888-1889). Des divisions fondamentales du sol français. Butlletin Littéraire, (II), 1-7 et 49-57. [Hay traducción al castellano, a cargo de I. Pérez-Villanueva, en J. Gómez, N. Ortega y J. Muñoz (eds.) (1982). El pensamiento geográfico (pp. 243-249). Madrid: Alianza, 1982.] 


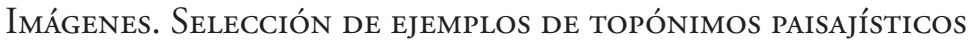

La selección de fotografías que presentamos a continuación tiene como propósito ofrecer un testimonio visual del alto grado de correlación entre nombres y paisajes que ofrecen numerosos topónimos -en el caso que nos ocupa, del dominio lingüístico del catalán-, caracterizados por tener una significación territorial (o geográfica) relevante. En relación con cada uno de los topónimos, además de aportar una imagen representativa, se anota su caracterización general y se da una referencia documental de los mismos, así como la referencia básica de su etimología (procedente, en todos los casos, de los diccionarios etimológicos del profesor Coromines, DECLC y OnoCat, citados en la bibliografía). Asimismo, se alude en cada caso a los principios toponímicos que consideramos que les son de aplicación.

Fuente de las imágenes: Archivo personal del autor

\section{a) Montsec}

El nombre Montsec (que etimológicamente equivale a "monte seco") se aplica a una de las sierras del Prepirineo leridano (y oscense) más destacadas, caracterizada en buena medida por su aridez. Documentado en 1044 como Silva de Montesico, se puede considerar como una aplicación directa del principio de transparencia. [Coromines, OnoCat, V: 381].

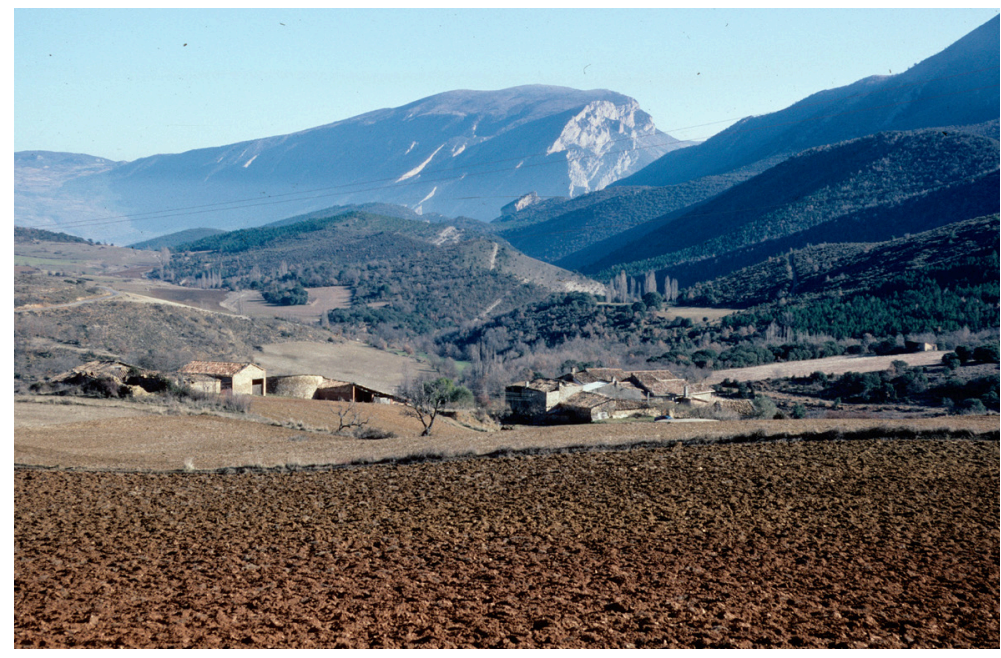

b) Comiols

Comiols es el topónimo que identifica uno de los pasos o collados más destacados entre el valle del Segre y la denominada Conca de Tremp, en el Prepirineo de Lleida. Documentado Comezols en 1068, etimológicamente se interpreta como una derivación de la forma latinizada Colles Mediolos (equivalente a "collados de 
en medio"). Su aplicación nos remite al principio de significatividad territorial. [Coromines, OnoCat, III: 417-418].

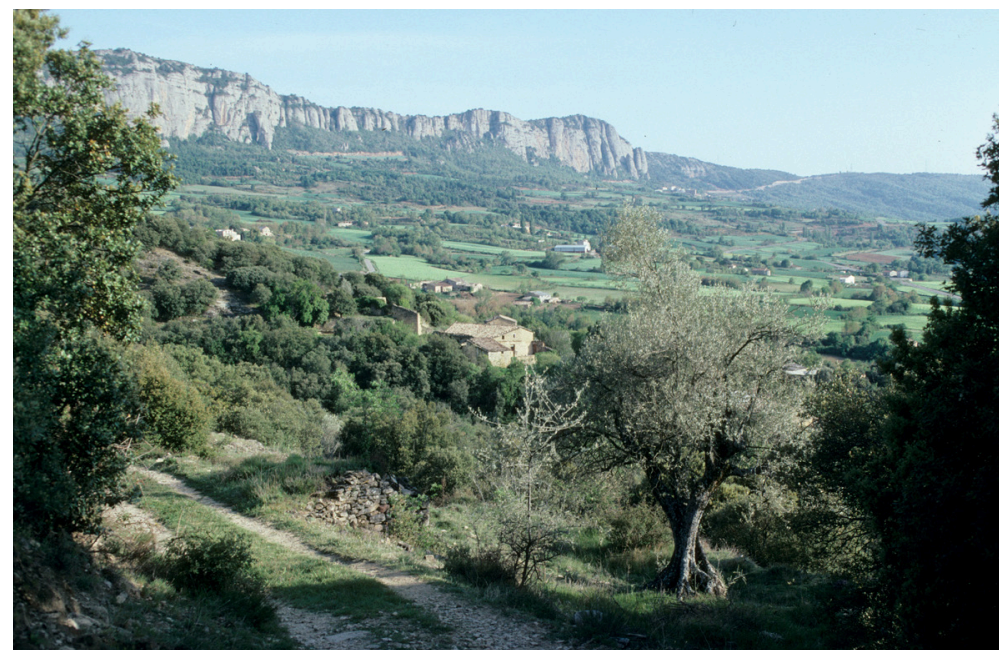

\section{c) Codó}

El nombre Codó (con esta grafía o con algunas variantes) aparece con cierta frecuencia en la toponimia del Pirineo catalán, aplicado específicamente a lugares orográficamente abruptos y rocosos. El ejemplo de la ilustración corresponde a la denominada Serra del Codó, o Roques del Codó, en el límite entre las comarcas del Pallars Jussà y la Alta Ribagorça, en la provincia de Lleida. Etimológicamente procede del latín Cos CoTIS, equivalente a "roca", y su aplicación en clave paisajística apunta al principio de significatividad territorial. [Coromines, OnoCat, III: 455].

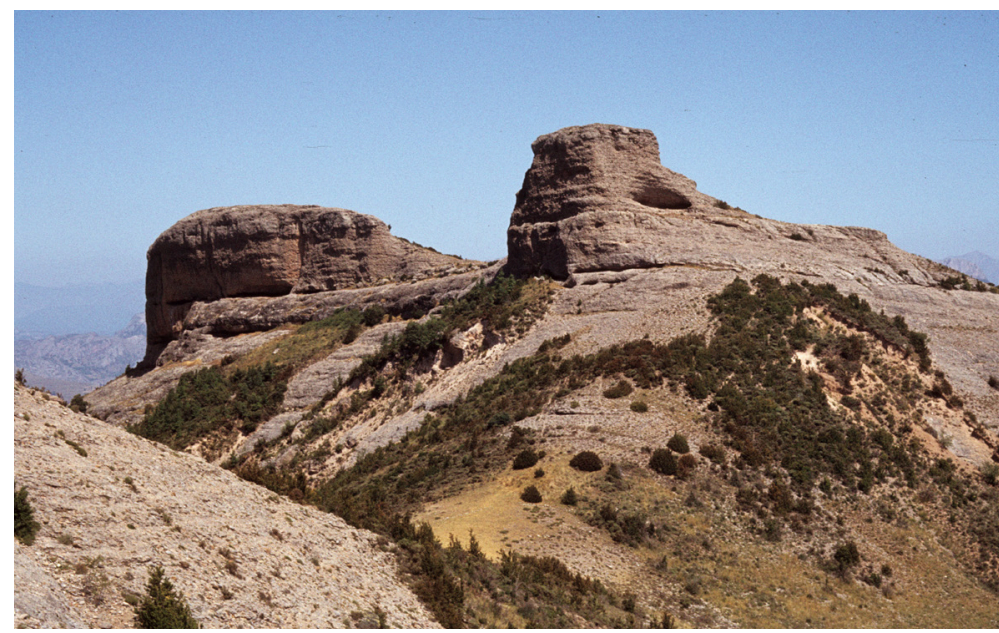


d) Riu Corb

El nombre de riu Corb -literalmente, "río curvo o sinuoso" - se aplica a uno de los pequeńos pero, sin embargo, largos riachuelos que drenan el extenso llano de Urgell en el occidente catalán, y que, a pesar de su escasez de caudal, tienen una gran relevancia fisiográfica y paisajística en el dominio geográfico en que se insertan. Documentado Rivo Curvo en 1198, su aplicación, teniendo en cuenta la horizontalidad estructural de su entorno, creemos que obedece claramente al principio de excepcionalidad. [Coromines, OnoCat, VI: 400. DECat, II: 923-925].

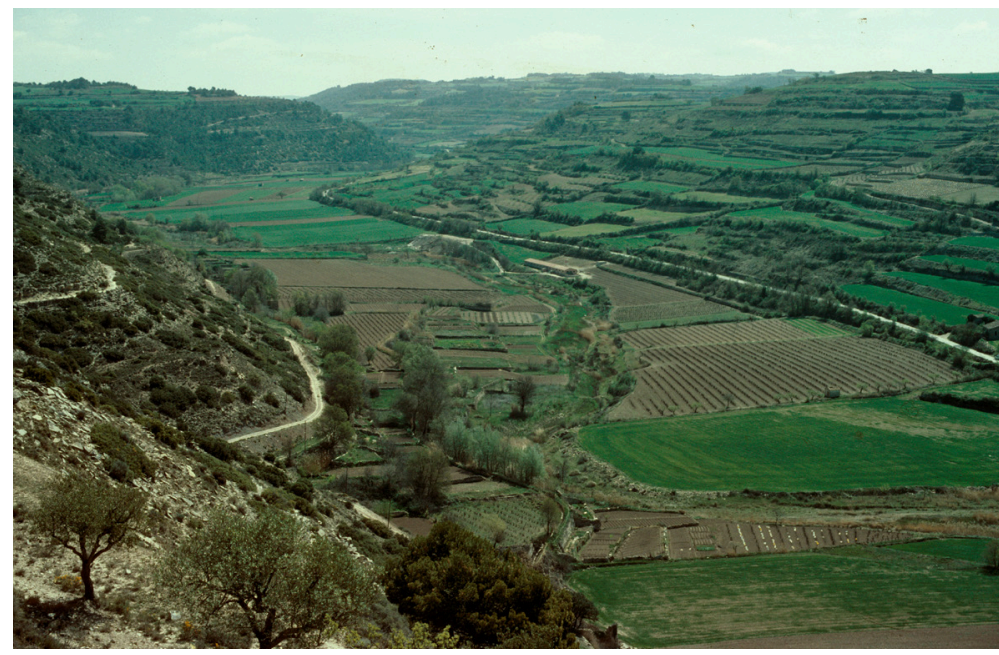

e) Montserrat

El topónimo Montserrat tiene también, más allá de su gran arraigo en el conjunto de la oronimia (o toponimia aplicada al medio físico) catalana, una muy estimable trascendencia paisajística. Su etimología -que apunta, literalmente, a la idea de "monte cortado" - alude de un modo inequívoco al carácter fracturado de su roca constitutiva, que, acentuado por la erosión, da lugar al inconfundible perfil (o skyline) de la montaña). Podemos considerarlo un nombre a medio camino entre los principios de transparencia y significatividad territorial. Documentado Monte serrate en el año 888. [Coromines, OnoCat, V: 383]. 


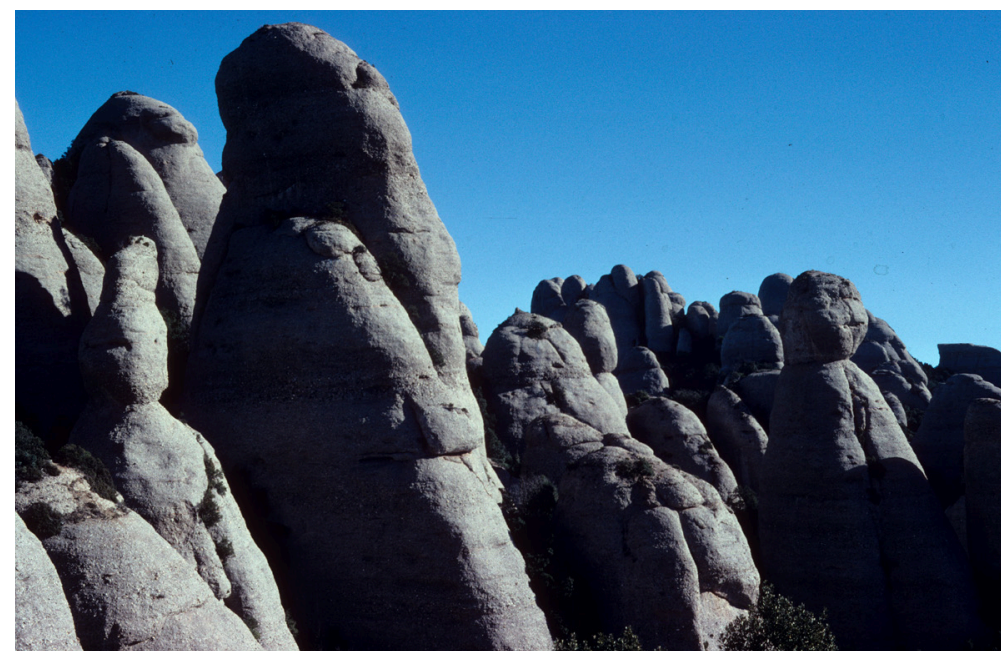

\section{f) Puigsacalm}

El nombre de Puigsacalm, documentado ad ipsa Calmo en 1105, alude a uno de los más destacados bastiones montañosos del Prepirineo Oriental. Formado a partir de la raíz prerromana KALMIS, "altiplanicie, llano elevado", el nombre alude específicamente a la parte culminante del macizo, de perfil horizontal, mientras que sus vertientes (y en especial la suroriental, en la imagen) presentan un carácter marcadamente abrupto. Tal contraste nos permite considerar este topónimo como un ejemplo significativo del principio de excepcionalidad. [Coromines, DECLCat, II: 437-440].

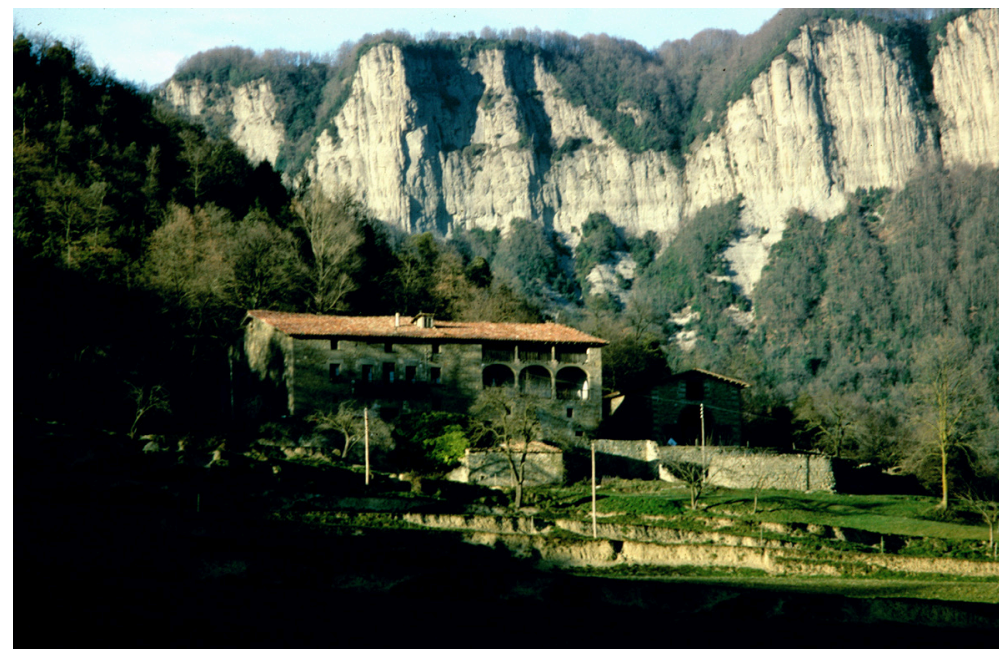




\section{g) Montseny}

Alusivo a una de las montañas más emblemáticas y de mayor altitud de la cordillera prelitoral catalana, el nombre de Montseny responde, en su génesis etimológica, a la cualidad de "montańa señal" o hito que se destaca con claridad en el horizonte. Documentado Montis Signi en 848, responde conjuntamente a los principios toponímicos de transparencia y de significatividad territorial. [Coromines, OnoCat, V: 381]. En la imagen, el Montseny (al fondo) desde el Pirineo.

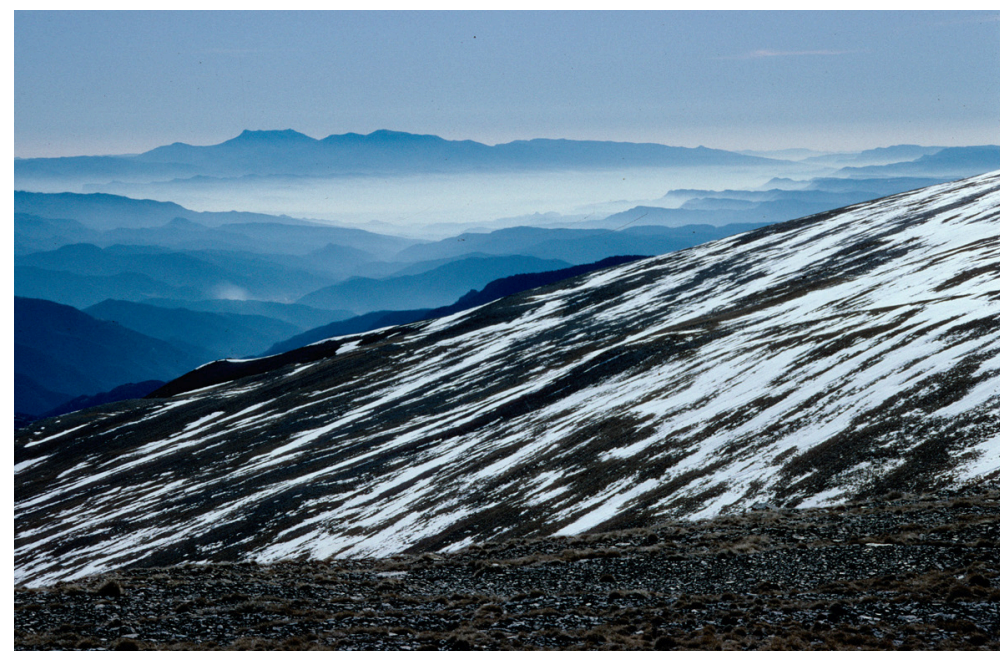

h) Vallès

El nombre Vallès, formado sobre la raíz latina VALLIS y aplicado desde antiguo a una de las comarcas paisajísticamente más bien diferenciadas del entorno de Barcelona, puede ser etimológicamente interpretado, según Coromines, como "territorio de los múltiples valles o riberas". Documentado Vallensem regionem en 827 o Comitatus Vallensis en 968, lo podemos situar, en cuanto a su génesis, a medio camino entre los principios de transparencia y de significatividad territorial. [Coromines, OnoCat, VII: 422-423]. 


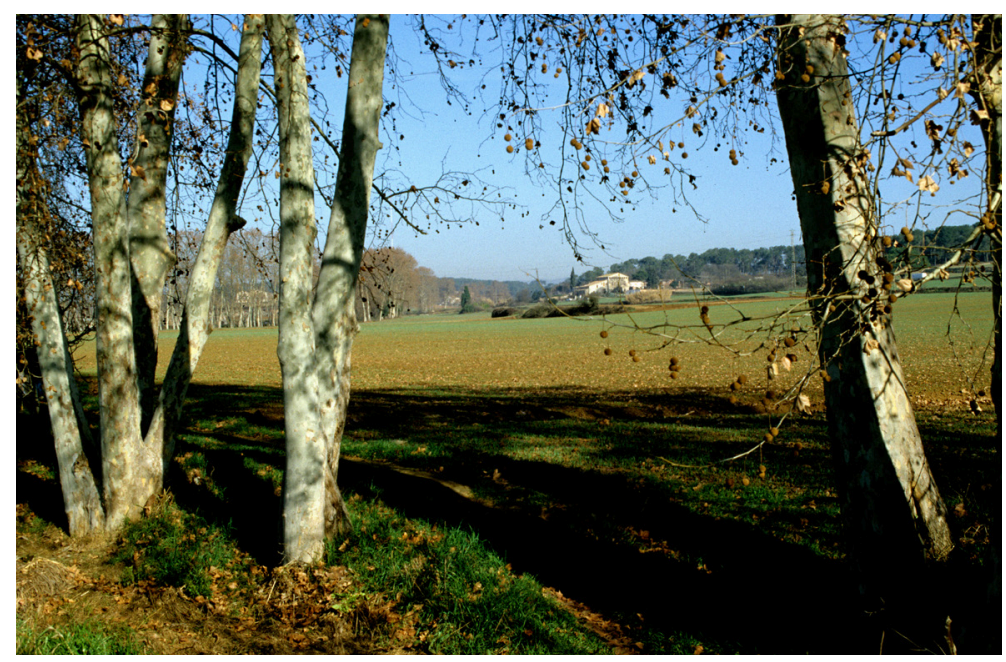

